\title{
Becoming a librarian BFF Three tips to connect with your students
}

A

the ACRL 2017 conference in Baltimore, Maryland, we presented a poster on a program called, "The Librarian BFF Program for Distance Graduate Students." ${ }^{1}$ The title is a tongue-in-cheek way of framing librarians to be students' and faculty's "best friend forever," which was our approach for providing a personalized librarian service to a specific group of users. With the connotation of being a "BFF," we adopted a more playful and intimate attitude to delivering the service.

During the poster presentation, we had many engaging discussions with the attendees, and we received a lot of inquiries about how we developed and implemented the program. Looking back at the questions, we noticed three general themes, and this article provides our answers to those questions with three tips for librarians who seek to add to their liaison and instruction repertoire.

The main purpose of the Librarian BFF Program was to provide a personalized service to students and faculty of an executive style, cohort-based, Doctor of Education program at the University of Alabama. It was a collaboration between the College of Education, McLure Education Library, and Gorgas Library, the main library at the University. The idea for the program stemmed from other personal librarian programs, such as the Yale University Personal Librarian program for undergraduate students; ${ }^{2}$ the University of North Carolina-Chapel Hill Libraries personal librarian program for transfer students; ${ }^{3}$ and the "Crazy Smart/Personal Librarian" program at Duke University Libraries for students who reside in a particular dormitory. ${ }^{4}$

Most of the personal librarian programs out there tend to focus on undergraduate students; however, we adopted the concept to serve a very specific group of graduate students. Our target audience were students in an Executive EdD program, which has components of both on-campus weekend residencies and online learning. Most of the students in the program did not live locally. They were adult students who had already accomplished a lot in their careers, but were returning to the classroom for the first time in a while, and therefore might not have been familiar with current research practice and technologies.

As the three-year program is a highly structured one, students have to plan the topic and research for their dissertation very early one. Our Librarian BFF Program sought to build personal relationships with the students by providing scaffolded instructions and individualized research consultations from the beginning of the program to the dissertation stage. The librarian was able to customize service to the students' needs by keeping track of their dissertation topics, while collaborating with the program direc-

Erica England is first-year experience librarian at Washington State University, email: erica.england@wsu. edu, and Leo S. Lo is associate university librarian at Old Dominion University Libraries, email: Ilo@odu.edu. Both are formerly of the University of Alabama.

(C) 2017 Erica England and Leo S. Lo 
tor to design instruction sessions at strategic points in the program.

As we presented the Librarian BFF Program at the ACRL conference, the most frequently asked questions from the attendees were:

1. How did you identify interested faculty to develop such a program?

2. How were you able to offer more than one-shot instruction sessions?

3. How did you get to "know" the students?

In answering the three questions, we develop the following three practical tips.

\section{Tip 1: Work with program directors}

Our goal was to promote and provide library instruction to users who need it. There are, however, many common obstacles that prevent librarians from achieving that goal. Many faculty simply do not want to have any library instruction sessions for their classes. Their reasons vary, but the bottom line is that librarians have a difficult time reaching students in those courses. Even faculty who are interested in librarians coming to their classes might still be quite protective of their class time, which means that librarians could only cover so much during those limited interactions with students, thus limiting the impact.

Some faculty are more willing to give up class time when they are out of town or at a conference. Librarians should of course take advantage of those opportunities, but the timing of those class times might not necessarily be optimal as to providing instruction "just in time" for assignments. Overall, it is difficult to find faculty who are open to truly partnering with librarians to incorporate information literacy/library research instruction into their classes.

Our solutions for this issue involve two key points. The first point is to adopt a problem-solving mentality. This requires a fundamental shift of a mindset from trying to sell a service to actively listening to the users' problems first. When we communicate with faculty, instead of selling what we have, we ask, "How can I make your job easier?" A curious mind is required for this approach, as in any qualitative inquiry, the true insight tends to come out only after probing and follow-up questions. However, bear in mind that there are many problems that librarians cannot solve for the faculty. But by asking and discussing, librarians can earn the trust of the faculty and can build a good relationship for future collaboration possibilities.

In order to achieve our goal of promoting and providing library instruction to users who need it, the second key point is therefore to strategically look for people with problems you can solve. One inconvenient truth is, while many faculty, especially tenure-track faculty, are tasked with teaching and their teaching is one factor in their tenure promotion process, it is often not the most important factor. Their research is usually the most important factor in their tenure and promotion process, particularly at large research universities. Therefore while most of the faculty care about their teaching, it is rarely their number one priority, which is why librarians often have a difficult time making inroads to those faculty's courses.

On the other hand, a program director is tasked with leading an entire program. Even though the director could be either tenured or on a tenure track, it is a much more visible position, with more responsibility than simply teaching several courses a year. Therefore, a successful program director must learn to delegate and collaborate. In addition, with the high workload program directors are burdened with, more likely than not, they are overworked and overwhelmed. Librarians can take advantage of this reality, and come to the rescue by listening to their problems, and try help solve some of them with library services and programs.

\section{Tip 2: Figure out where you fit in the program}

One of our goals was to have more than a one-shot introductory session for students. Nontraditional students are already over- 
whelmed at the beginning of their programs for numerous reasons: they have not performed research in quite some time, so they may no longer have sufficient research skills; some students may need to learn the technology that is required to perform research; and many students have outside responsibilities, such as careers and families. Bombarding them with everything they would need to know about the library at the beginning of their program would only add to their anxiety. In order to truly provide a personalized service to students and faculty, we recognized that one introductory session at the beginning of the program was insufficient, and that we would need to design a tailor-made program that would work for both faculty and students.

Creating this tailor-made program was met with some obstacles. Since the students in the executive program only met face-toface once a month, we knew that we were working with limited class time. It is challenging to build a program with multiple instruction sessions without a close partnership with faculty members or the program director, and unfortunately there are some faculty members who do not see the value of library instruction or how it relates to student success. It can also be very overwhelming for the librarian to work with a large number of students at one time.

Our solutions to these obstacles were two-fold. First, it is much easier to work with smaller cohorts. It will be more manageable to work with a handful of students rather than an entire program, both in time management and in keeping track of individual student's research. Additionally, cohorts are designed to allow students to build an immediate network of colleagues, so they tend to be more personal in nature. This will only help to make close, personal connection with students, since everyone involved is already "friends."

It is important to look at the overall structure of the entire degree program and figure out where students will need help with their research. An introduction to the library in their first semester is usually not enough, therefore try to work with the receptive individual instructors throughout the course of the entire program to prepare students with the skills that they will need to succeed. It is extremely important to strategically place library instruction at a period of time that the skills learned are beneficial to students' research and assignments. Keep in mind that the beginning of the program is overwhelming for nontraditional students, so try not to overload them with everything they will need to know in one session at the beginning of their program. Instead, plan to meet with them a few times throughout the course of their first semester to work with them, as they need the necessary research skills for that time to complete assignments, and from there build upon these foundational skills.

\section{Tip 3: Get personal with students}

To become "BFFs" with the students, we had to build a close relationship with the students to follow their research each step of the way throughout the entire program. Since the students must have a dissertation ready in a short period of time, we aimed to identify gaps in their research knowledge and to let them know about resources that would meet their individual research needs. We are more than just instructor librarians, we care about their individual research, goals, and success.

Perhaps one of the largest obstacles of this method is the time commitment for the librarian. Working with multiple students and keeping track of their individual research topics could easily inundate someone. There is also the dilemma of never seeing the same student again, so why bother? It might also be difficult for librarians to get to know the students. During our ACRL poster presentation, this was a common question asked by attendees.

The solution to these particular obstacles were intertwined. A simple way to create personal relationships and get to know the students is to approach the situation as a potential for making new friends. At the 
introductory session at the beginning of their program, we took the time to get to know the students. We asked them about themselves, what their interests were, what their hobbies were, etc. And the librarians also shared-we told them about ourselves and allowed our personalities to shine. This immediately made for a more comfortable, informal setting where they felt more at ease in asking questions. Throughout the multiple instruction sessions, we allowed them to see our mistakes and struggles so that they would know that they were not the only ones who sometimes have difficulty in finding information.

Once the students were more at ease, their research anxiety faded, and they were more comfortable with interacting with the librarian and asking for specific research help outside of the library instruction sessions. In order to keep track of individual research topics, the librarian started taking notes whenever interacting with students. These notes eventually turned into a spreadsheet that included students' names, their research topic (and any derivatives of it), and what had already been done to find resources. That way, whenever a student contacted the librarian, the conversation could pick up right where it had left off.

\section{Action plan}

With these three the tips in mind, we have come up with an action plan for liaison or instruction librarians who would like to immediately apply these methods to their work.

Step 1: Identify cohort-based programs in your areas. This could be accomplished by simply looking at departmental websites or catalogs. Another way to find the information is to ask the administrative assistants of the various academic departments.

Step 2: Once you have identified the programs, the next step is to contact the program directors and listen to their challenges. While the conversations could be informal and casual, you should treat them as qualitative interviews, and ask follow-up and probing questions, with the intention of collecting rich data and analyzing these data later.

Step 3: Develop and propose scaffolded instruction services to help the program directors. After analyzing the conversations you have with the program directors, it is time to develop instruction that specifically solves some of the challenges that the program directors face.

Step 4: Once you are in the classroom or have interactions with the students, don't be afraid to show your personality. You will hopefully be working with these same students more than once, or perhaps even throughout their university careers, let them know that. One effective way to establish a relationship is to open yourself up to your students first.

Step 5: Start keeping track of their research interests early on; being organized early on will save you a lot of time later. Use a spreadsheet to systematically keep track of the students' research interests, thesis/dissertation topics, and your notes on research consultations with them. Be their research $B F F$, and they will appreciate it.

When we began our "Librarian BFF" program, we treated it as an experiment. With an open mind and playful attitude, we were more interested in learning how to best help the students and the program directors, rather than focusing on achieving "success."

As a result, we are now applying what we have learned to many other projects at other institutions. Therefore, our final bonus tip is: make the project fun for you to do, and pay attention to all the little lessons you can learn along the way.

\section{Notes}

1. Erica England and Leo Lo, "The Librarian BFF Program for Distance Graduate Students" (poster presentation, ACRL 2017, Baltimore, Maryland, March

(continues on page 515) 
should build search momentum and forward thinking without inciting backtracking and second-guessing.

Librarians encounter research anxiety in their scholarly projects, but they also face the challenge of quelling patron research anxiety. In that sense, librarians are counselors. This metaphor extends to other aspects of the profession, ahem chatty public patrons, but for the discussion at hand, librarians are the soothers of uneasy paper writers.

One of our greatest assets is our empathy. Having spent hours ourselves audibly frustrated with uncooperative databases or unsuccessful in seeking a proper citation style for an unusual document, we can relate. So often the answer to a reference question is a pep talk rather than an actual answer. Who better to treat research anxiety than those who are intimately familiar with its symptoms?

Although we have gotten librarianship down to a science, research is equal parts diligence as it is skill. It can be just as important to impart to our patrons that they need to invest time as it is to demonstrate specific resources. Unfortunately, librarians are frequently expected to have the answer, and expected to have it quickly. This expectation unto itself can be a source of anxiety.

Rather than feeling like a failure each time "the answer" turns out to be a discussion of various strategies instead of a distinct book or website, librarians can ease their own anxiety in knowing that the process is rarely simple. Experience bolsters the

\section{Experience bolsters the confidence that research isn't consistently laser sharp precision. Its lines are some- times safety-scissor jagged.}

confidence that research isn't consistently laser sharp precision. Its lines are sometimes safety-scissor jagged.

Settling in to that imperfect reality gracefully, with the unwavering resolve to search, is a learned skill. The library professional's determination to navigate a tangled research web with confidence is an anti-anxiety tool.

Uncertainty is uncomfortable, but it is also unavoidable. A popular technique to thwart anxiety is to learn to experience uncertainty without exaggerated regard, to allow it to exist without triggering the worry alarms. Let uncertainty take up residence in the brain without rent. There are natural inlets for anxiety in the research process: uncertainty in resources, in search results, and in the many permutations of an answer.

The trendy "keep calm and ask a librarian" t-shirt is wise beyond its novelty. The answer that a patron is seeking can be that calm.

We all need reassurance that the end goal is not necessarily a definitive answer. Research is a systematic tour through the information troves, ending with a confident conclusion that the best effort has been put forth. To quell research anxiety, one has to accept uncertainty.

("Becoming a librarian BFF," continues from page 513)

22-25, 2017), https://s4a.goeshow.com/ temp/handouts/427A9E3E-8A51-E511 -B4CD-0025B3A62EEE/2069_Librarian \%20BFF\%20Program.pdf.

2. Yale University Library, "About the Personal Librarian Program," Yale University Library, accessed May 16, 2017, http://web. library.yale.edu/pl.

3. UNC University Libraries, "Personal
Librarian Program for Transfer Students," University of North Carolina-Chapel Hill University Libraries, accessed May 16, 2017, http://library.unc.edu/personal-librarian/.

4. Duke University Libraries, "Crazy Smart/Personal Librarian Program," Duke University Libraries, accessed May 16, 2017 , https://library.duke.edu/support/crazy -smart-personal-librarian-program. $\boldsymbol{z}$ 